\title{
Ekstrakcija bioaktivnih spojeva iz duhanskog otpada primjenom eutektičkih otapala
}

https://doi.org/10.15255/KUI.2020.010

KUI-46/2020

Izvorni znanstveni rad

Prispjelo 25. veljače 2020 .

Prihvaćeno 19. svibnja 2020.

\author{
M. Banožić,a* M. Matić, S. Šafranko, A.-M. Cikoš,a \\ M. Jakovljević, M. Molnara i S. Jokića \\ a Sveučilište Josipa Jurja Strossmayera u Osijeku, Prehrambeno-tehnološki fakultet, Osijek, Hrvatska \\ b Sveučilište u Mostaru, Agronomski i prehrambeno-tehnološki fakultet, \\ Mostar, Bosna i Hercegovina
}

Ovo djelo je dano na korištenje pod Creative Commons Attribution 4.0 International License

\section{Sažetak}

Duhanski otpad je kruti otpad, a njegove vrste međusobno se razlikuju po granulaciji i mjestu izdvajanja u procesu proizvodnje. Cilj ovog rada bio je istražiti učinkovitost eutektičkih otapala u ekstrakciji bioaktivnih komponenti iz duhanskog industrijskog otpada (refabrikat, rebro i prašina). Ispitan je utjecaj procesnih parametara (vrijeme miješanja, temperatura i udio vode u otapalu) na svojstva samog ekstrakta (ukupne fenole, antiradikalnu aktivnost, udio klorogenske kiseline i rutina). Metodom odzivne površine određeni su optimalni parametri ekstrakcije (30 min, $70{ }^{\circ} \mathrm{C}, 29,99 \%$ vode). Provedeno istraživanje ogleda se u maksimalnom iskorištavanju nusproizvoda duhanske industrije, a rezultira visokovrijednim ekstraktima koji se mogu implementirati u druge procese i proizvode.
\end{abstract}

\section{Ključne riječi}

Duhanski otpad, eutektička otapala, ekstrakcija, bioaktivne komponente

\section{Uvod}

Duhan (Nicotiana tabacum L.) jedna je od najčešće uzgajanih biljaka koje se ne upotrebljavaju za prehranu te se uzgaja u preko 130 zemalja svijeta. ${ }^{1}$ Različitost područja na kojima se uzgaja kao i primijenjene tehnologije rezultiraju različitim kemijskim sastavom. Glavnina uzgojenog duhana upotrebljava se za preradu u duhanske proizvode, poglavito cigarete i cigare. Prerada duhana rezultira i nastankom nusproizvoda, duhanskog otpada, koji može biti poljoprivredni (izdvaja se na polju), industrijski (izdvaja se tijekom procesiranja lista) i potrošački (nastaje nakon potrošnje duhanskih proizvoda). ${ }^{2}$ Duhanski industrijski otpad podrazumijeva rebro lista koje se izdvaja u procesu ižiljavanja/stripsiranja, zatim refabrikat i prašinu koji podrazumijevaju frakcije male granulacije koje potječu izravno od lamine lista. ${ }^{2,3}$ Rebro je dio biljke duhana, koji se pruža iz stabljike. Potrebno ga je ukloniti tijekom prerade lista jer uzrokuje daljnje probleme u obradi cigareta, kao što su rupe $i$ promjene u karakteristikama tijekom pušenja. ${ }^{4}$ Dio tako nastalog otpada, ako podliježe posebnim zahtjevima, može se iskoristiti za proizvodnju rekonstruiranog duhana/duhanske folije (engl. reconstituted tobacco). Zbrinjavanje takvih vrsta otpada postaje pitanje od javnog interesa zbog njihovih potencijalnih utjecaja na okoliš i ljudsko zdravlje. ${ }^{5,6}$
Nekoliko je istraživanja pokazalo da je duhanski otpad potencijalno primjenjiv izvor bioaktivnih spojeva, $, 8,9,9,10$ poglavito zbog neuobičajene dominacije klorogenskih kiselina (klorogenska kiselina, neoklorogenska kiselina i kriptoklorogenska kiselina) te rutina. ${ }^{11}$ Klorogenska kiselina i rutin su visoko-vrijedni prirodni fenolni spojevi koji se upotrebljavaju u farmaceutskoj i kemijskoj industriji, a njihova identifikacija i kvantifikacija u duhanskom otpadu također je od velike važnosti. ${ }^{12}$ Rutin je jedan od medicinski najvažnijih flavonoida. Prirodni je antioksidans, a u osušenom duhanu ima ga oko $1 \%$, što duhan čini dobrim izvorom tog spoja. Zanimljivo je napomenuti da fermentirani listovi duhana sadrže manje rutina $(0,5 \%)$ od nefermentiranih $(1,5 \%)$. Razlog tome je što se rutin razgrađuje djelovanjem enzima u procesu fermentacije. ${ }^{13}$ "Zaštitna" svojstva rutina uključuju antiradikalno, antimikrobno, antikancerogeno i kardiovaskularnozaštitno djelovanje. ${ }^{14}$ Klorogenska kiselina je kafeoilkilna kiselina, koja posjeduje širok raspon bioloških aktivnosti, kao što su antibakterijska, antiradikalna, antikancerogena i antimutagena aktivnost. ${ }^{12}$ Klorogenska kiselina i drugi polifenoli imaju široku primjenu u medicini, kemijskoj industriji i prehrambenoj industriji. Dosadašnji izvori klorogenske kiseline veoma su skupi i teško dostupni, te je veoma važno pronaći novi izvor na njihovu proizvodnju. ${ }^{9}$

\footnotetext{
*Autor za dopisivanje: Marija Banožić, mag. ing. preh.

e-pošta: mbanozic@ptfos.hr
} 
Zelene tehnike ekstrakcije trenutačno su jedno od ključnih područja u polju separacijskih znanosti jer imaju cilj očuvanje okoliša i smanjenje mogućih negativnih učinaka na ljudsko zdravlje. Zelene tehnologije ekstrakcije smanjuju upotrebu organskih otapala nudeći nove ekološki prihvatljive tehnike te razvoj novih zelenih otapala. ${ }^{15}$ Konvencionalni procesi ekstrakcije su zahtjevni, dugotrajni, uključuju velike količine otapala, a mogu dovesti do degradacije ciljanih molekula i djelomičnog gubitka hlapljivih tvari. ${ }^{16}$ Unatoč visokoj potrošnji energije i velikoj količini otapala, iskorištenje je često veoma nisko. ${ }^{17}$ Stoga se u posljednje vrijeme razmatraju sigurnije i učinkovitije tehnike ekstrakcije utemeljene na razumnom kompromisu između ekonomskih, socijalnih i ekoloških zahtjeva. Na temelju takvih zahtjeva razvijena su eutektička otapala (engl. Deep Eutectic Solvents - DESs). DES kao novi sustav otapala sastoji se od dvije ili više komponenti koje se ponašaju kao donori i akceptori vodikovih veza tvoreći eutektičku smjesu s nižom točkom taljenja od njegovih pojedinačnih komponenti. ${ }^{18,19}$ Lako se pripremaju, visoke su čistoće i niske cijene, nezapaljivi su, netoksični, sigurni, jeftini i lako dostupni. Kako bi se postigla veća učinkovitost ekstrakcije eutektičkim otapalima, optimiraju se uvjeti ekstrakcije, uključujući temperaturu, vrijeme i udio vode u otapalu. ${ }^{15}$

Stoga, cilj ovog istraživanja je:

a) provesti "screening" različitih eutektičkih otapala i različitih vrsta duhanskog otpada te po odabranom kriteriju udjela ukupnih fenola u dobivenim ekstraktima odabrati najbolje otapalo i vrstu otpada koja će se upotrebljavati za daljnju optimizaciju;

b) provesti ekstrakciju eutektičkim otapalima, prema Box-Behnkenovom planu pokusa, sa zagrijavanjem od 50 do $90{ }^{\circ} \mathrm{C}$, udjelom vode $10-30 \%$ i trajanjem miješanja od 30 do 90 min s najboljim otapalom na najpovoljnijem otpadu;

c) odrediti udio ukupnih fenola po metodi FolinCiocalteu te antiradikalnu aktivnost dobivenih ekstrakata testom DPPH;

d) odrediti udio dominantnih komponenti (klorogenska kiselina i rutin) u dobivenim ekstraktima primjenom metode HPLC;

e) odrediti utjecaj nezavisnih varijabli (temperatura, vrijeme miješanja i udio vode u otapalu) na zavisne varijable (udio ukupnih fenola, antiradikalna aktivnost ekstrakata te udjele rutina i klorogenske kiseline);

f) provesti optimizaciju procesa ekstrakcije uz primjenu programa Design Expert ${ }^{\circledR}$, metodom odzivnih površina na osnovi eksperimentalnih podataka dobivenih prema Box-Behnkenovom planu pokusa.

\section{Eksperimentalni dio}

\subsection{Materijali}

Duhanski otpad (refabrikat, prašina i rebro) ustupila je tvornica za preradu duhana "Fabrika duhana Sarajevo" (Sarajevo, Bosna i Hercegovina) članica grupacije British American Tobacco u 2018. godini. Uzorci su prikupljeni u suhom stanju i samljeveni na mlinu (MRC Sample mill CSM/450-C, Holon, Izrael). U radu je upotrijebljen metanol (J. T. Baker, New Jersey, PA, SAD), Folin - Ciocalteu reagens (Sigma-Aldrich Taufkirchen, Njemačka), $\mathrm{NaCO}_{3}$ Sigma-Aldrich (Taufkirchen, Njemačka), fosforna kiselina (J. T. Baker, New Jersey, PA, SAD), standard klorogenske kiseline, čistoće 96,63\% (Dr. Ehrenstorfer $\mathrm{GmbH}$ Augsburg, Njemačka), standard rutina čistoće 94,56 \% (Dr. Ehrenstorfer $\mathrm{GmbH}$, Augsburg, Njemačka).

\subsection{Priprema eutektičkih otapala}

Eutektička otapala (DES) pripremljena su s kolin kloridom kao akceptorom vodika i s 15 različitih donora vodika u molarnom omjeru prikazanom u tablici 1. Tako pripremljeno otapalo zagrijavalo se uz konstantno miješanje sve do formiranja stabilne i homogene smjese.

Tablica 1 - Popis pripremljenih DES-ova upotrijebljenih za ekstrakciju bioaktivnih komponenti iz duhanskog otpada

Table 1 - List of DESs prepared and tested for the extraction of bioactive compounds from tobacco waste

\begin{tabular}{|c|c|c}
\hline Akceptor vodika & Donor vodika & Molarni omjer \\
\hline kolin klorid & urea & $1: 2$ \\
\hline kolin klorid & N-metilurea & $1: 3$ \\
\hline kolin klorid & glukoza & $1: 1$ \\
\hline kolin klorid & ksilitol & $1: 1$ \\
\hline kolin klorid & sorbitol & $1: 1$ \\
\hline kolin klorid & butan-1,4-diol & $1: 2$ \\
\hline kolin klorid & etan-1,2-diol & $1: 2$ \\
\hline kolin klorid & glicerol & $1: 2$ \\
\hline kolin klorid & acetamid & $1: 2$ \\
\hline kolin klorid & jabučna kiselina & $1: 1$ \\
\hline kolin klorid & limunska kiselina & $1: 2$ \\
\hline kolin klorid & malonska kiselina & $1: 1$ \\
\hline kolin klorid & oksalna kiselina & $1: 1$ \\
\hline kolin klorid & mliječna kiselina & $1: 1$ \\
\hline kolin klorid & levulinska kiselina & $1: 1$ \\
\hline
\end{tabular}

\subsection{Ekstrakcija bioaktivnih komponenti iz duhanskog otpada}

Za potrebe "screeninga", $50 \mathrm{mg}$ osušenih i samljevenih uzoraka duhanskog otpada pomiješano je $\mathrm{s} 1 \mathrm{ml}$ otapala, tj. smjesom DES i $20 \%(v / v)$ demineralizirane vode. Smjesa 
je zagrijavana pri temperaturi $50{ }^{\circ} \mathrm{C}$ kroz 30 min. Tijekom postupka optimizacije, DES-ovi su pripremljeni s različitim udjelima vode i miješani pri različitim temperaturama kroz različito vrijeme prema Box-Behnkenovom planu pokusa, kako je to prikazano u tablici 4. Nakon završetka ekstrakcije smjesa je centrifugirana u trajanju od $15 \mathrm{~min}$, supernatant je dekantiran $(200 \mu \mathrm{l})$ te mu je dodano $800 \mu \mathrm{l}$ metanola. Zatim je tako pripremljen ekstrakt filtriran kroz PTFE filtar $(0,45 \mu \mathrm{m})$. Svi ekstrakti pripremljeni su u dvije paralele.

\subsection{Određivanje ukupnih fenola}

Ukupni fenoli određivani su spektrofotometrijski metodom po Folin-Ciocalteu detaljnije objašnjenoj u drugom radu. ${ }^{20}$ Intenzitet obojenja mjeren je određivanjem apsorbancije na $765 \mathrm{~nm}$ u odnosu na slijepu probu. Rezultati su izračunati prema kalibracijskim krivuljama masenog udjela galne kiseline i ukupnih fenola te izraženi kao mg ekvivalenata galne kiseline (GAE) po gramu suhe tvari. Sva mjerenja rađena su u tri paralele.

\subsection{Određivanje antiradikalne aktivnosti}

Antiradikalna aktivnost ekstrakata određena je spektrofotometrijski prema metodi DPPH opisanoj detaljnije $u$ drugom radu. ${ }^{20}$ Mjerenje je provedeno na valnoj duljini od $517 \mathrm{~nm}$, a rezultati izraženi kao postotci aktivnosti vezanja radikala (\% DPPH). Sva mjerenja rađena su u tri paralele.

\subsection{Tekućinska kromatografija visoke djelotvornosti (HPLC)}

Sadržaj polifenola određen je pomoću uređaja HPLC (Agilent technology 1260 Infinity II). Instrument je opremljen kvaternom pumpom, autosamplerom, termostatiranom kolonom te detektorom niza dioda (DAD). Upotrijebljena je kolona Zorbax Eclipse Plus C18 (veličine čestica $10 \times 4,6 \mathrm{~mm}, 5 \mu \mathrm{m}$ ). Analiza je provedena pri sobnoj temperaturi $\left(22^{\circ} \mathrm{C}\right)$. Udio klorogenske kiseline i rutina određen je metodom detaljnije opisanoj u radu Banožić et al. ${ }^{8}$

\subsection{Optimiranje procesa ekstrakcije duhanskog otpada s eutektičkim otapalima primjenom metode odzivnih površina}

Za procjenu utjecaja procesnih parametara (vrijeme, temperatura i udio vode $\mathrm{u}$ otapalu) na udio ukupnih fenola, antiradikalnu aktivnost te na udio klorogenske kiseline i rutina u duhanskom otpadu primijenjen je BoxBehnkenov plan pokusa. Ispitan je utjecaj tri različite nezavisne varijable: vrijeme miješanja $\left(X_{1}\right)$, temperatura zagrijavanja $\left(X_{2}\right)$ i udio vode u otapalu $\left(X_{3}\right)$ (tablica 2$)$.

Prema Box-Behnkenovom planu pokusa provedeno je 17 eksperimenata ekstrakcije. Eksperimentalno dobiveni podatci aproksimirani su s polinomom drugog reda odnosno matematičkim modelom odzivnih površina. Na osnovi dobivenog matematičkog modela (polinoma) konstruirane su odzivne površine. One omogućavaju vizualni prikaz utjecaja ispitivanih parametara na promatrane procese. Procjena koeficijenata modela nelinearnom regresijskom analizom, statistička analiza (ANOVA) značajnosti ispitivanih parametra na promatrane procese te numerička optimizacija ispitivanih procesnih parametara provedena je primjenom softverskog paketa Design-Expert $^{\circledR}$, v.7 (Stat Ease, Minneapolis, SAD).

\section{Rezultati i rasprava}

Za potrebe odabira najboljeg otapala kao i najpogodnije vrste duhanskog otpada proveden je "screening" 15 različitih otapala i tri vrste otpada (duhanska prašina, rebro i refabrikat). Kao kriterij za odabir najboljeg otapala i otpada upotrijebljen je udio ukupnih fenola prema FolinCiocalteu metodi. Rezultati "screeninga" prikazani su u tablici 3.

S obzirom na rezultate dobivenih ukupnih fenola, uspoređene s kalibracijskim pravcem za galnu kiselinu, usporedivši tri otpada, rezultati su pokazali da je najveći udio ukupnih fenola u refabrikatu te se kao najpogodnije otapalo pokazao kolin klorid/etilen glikol. Za razliku od drugih eutektičkih smjesa s kolin kloridom, kolin klorid/etilen glikol ima nisku viskoznost, kao posljedica velikog broja vodikovih veza između komponenti otapala, van der Waalsovih sila između molekula te veličine iona. ${ }^{19}$ Taj DES se pokazao dobrim otapalom za acetaminofen, komponentu s analgetičkim i antipiretičkim djelovanjem ${ }^{21}$ kao i dobro otapalo za ekstrakciju fenolnih spojeva u lišću masline, ${ }^{22}$ fenolnih spojeva u kori citrusa, ${ }^{23}$ rosmarinske kiseline i rosmarinske kiselina-3'-glukozida iz obične celinščice (Prunella vulgaris L.) ${ }^{24}$ te katehina iz zelenog čaja. ${ }^{25}$ Također, u našim prethodnim istraživanjima, gdje su fenolne komponente ekstrahirane uz pomoć vode u subkritičnom stanju ${ }^{10}$ ili ekstrakcijom potpomognutom ultrazvukom, ${ }^{7}$ pokazano je da je refabrikat, kao vrsta duhanskog industrijskog otpada najbogatiji ciljanim bioaktivnim spojevima. Nakon provedenog "screeninga" na odabranom uzorku refabrikata s odabranim otapalom kolin klorid/etilen glikolom, na temelju Box-Behnkenovog plana pokusa (tablica 4) provedene su ekstrakcije tijekom kojih su mijenjani parametri ekstrakcije: vrijeme miješanja (od 30 do $90 \mathrm{~min}$ ), temperatura miješanja (od 30 do $70{ }^{\circ} \mathrm{C}$ ) te udio vode u otapalu (od 10 do $30 \%$ ). U tako dobivenim ekstraktima, ispitivan je udio fenola, antiradikalna aktivnost te udio rutina i klorogenske kiseline kao ciljanih spojeva. 
Vrijednosti ukupnih fenola kretale su se između 5,30 mgGAE/g za uzorak refabrikata ekstrahiran pri uvjetima $60 \mathrm{~min}, 30{ }^{\circ} \mathrm{C}$ i $10 \%$ vode i $14,75 \mathrm{mg} \mathrm{GAE} / \mathrm{g}$ za refabrikat ekstrahiran pri uvjetima $60 \mathrm{~min}, 70{ }^{\circ} \mathrm{C}$ i $30 \%$ vode. Nešto veće vrijednosti dobivene su u našem prethodnom istraživanju gdje se kao otapalo upotrebljavala voda u subkritičnom stanju i gdje su se vrijednosti ukupnih fenola za refabrikat kretale između 7,72 i 13,62 mg GAE/g. ${ }^{10} \quad$ Vrijednosti antiradikalne aktivnosti kretale su se od 22,56\% za uzorak refabrikata ekstrahiran pri uvjetima $90 \mathrm{~min}, 50{ }^{\circ} \mathrm{C}$ i $10 \%$ vode do 44,68 \%. Također, kao i kod sadržaja ukupnih fenola, zabilježene su vrijednosti nešto niže nego kod ekstrakcije subkritičnom vodom. ${ }^{10}$

Tablica 2 - Nekodirane i kodirane razine nezavisnih varijabli korištenih u RSM dizajnu

Table 2 - Coded and uncoded levels of independent variables used in RSM design

\begin{tabular}{l|c|c|c|c}
\hline Nezavisne varijable & Oznaka & Donja (-1) & Centralna (0) & Gornja (1) \\
\cline { 3 - 5 } vrijeme miješanja/min & $X_{1}$ & 30 & 60 & 90 \\
\hline temperatura $/{ }^{\circ} \mathrm{C}$ & $X_{2}$ & 30 & 50 & 70 \\
\hline udio vode u otapalu /\% & $X_{3}$ & 10 & 20 & 30 \\
\hline
\end{tabular}

Tablica 3 - Rezultati "screeninga" za tri vrste duhanskog otpada (refabrikat, duhanska prašina i rebro) s 15 različitih eutektičkih otapala Table 3 - Screening results for three types of tobacco waste (scrap, dust, and midrib) and 15 eutectic solvents

\begin{tabular}{l|l|c|c|c}
\hline \multirow{2}{*}{$\begin{array}{l}\text { Red. } \\
\text { broj. }\end{array}$} & Otapalo & \multicolumn{3}{|c}{ Vrsta duhanskog otpada } \\
\hline 1. & kolin klorid/urea & 9,00 & Prašina/mg GAE/g & Rebro/mg GAE/g \\
\hline 2. & kolin klorid/N-metilurea & 5,40 & 7,60 & 6,70 \\
\hline 3. & kolin klorid/glukoza & 2,25 & 4,25 & 3,60 \\
\hline 4. & kolin klorid/ksilitol & 3,45 & 2,10 & 3,05 \\
\hline 5. & kolin klorid/sorbitol & 5,05 & 3,15 & 2,95 \\
\hline 6. & kolin klorid/butan-1,4-diol & 8,05 & 4,25 & 4,65 \\
\hline 7. & kolin klorid/etan-1,2-diol & 11,00 & 2,90 & 4,80 \\
\hline 8. & kolin klorid/glicerol & 2,60 & 8,75 & 8,85 \\
\hline 9. & kolin klorid/acetamid & 9,80 & 5,10 & 4,40 \\
\hline 10. & kolin klorid/jabučna kiselina & 8,60 & 8,70 & 8,25 \\
\hline 11. & kolin klorid/limunska kiselina & 6,00 & 3,85 & 5,00 \\
\hline 12. & kolin klorid/malonska kiselina & 9,20 & 8,45 & 1,90 \\
\hline 13. & kolin klorid/oksalna kiselina & 4,95 & 3,50 & 4,05 \\
\hline 14. & kolin klorid/mliječna kiselina & 7,00 & 8,10 & 3,15 \\
\hline 15. & kolin klorid/levulinska kiselina & 9,10 & 8,55 & 7,95 \\
\hline
\end{tabular}

Tablica 4 - Eksperimentalna matrica pokusa

Table 4 - Experimental design used in RSM

\begin{tabular}{c|c|c|c}
\hline RUN & Vrijeme miješanja i zagrijavanja/min & Temperatura miješanja $/{ }^{\circ} \mathrm{C}$ & Udio vode u otapalu/\% \\
\hline 1. & 60 & 30 & 30 \\
\hline 2. & 60 & 50 & 20 \\
\hline 3. & 30 & 70 & 20 \\
\hline 4. & 90 & 50 & 30 \\
\hline 5. & 30 & 50 & 10 \\
\hline 6. & 60 & 30 & 10 \\
\hline 7. & 90 & 50 & 10 \\
\hline 8. & 90 & 30 & 20 \\
\hline 9. & 90 & 70 & 20 \\
\hline 10. & 60 & 70 & 30 \\
\hline 11. & 60 & 70 & 10 \\
\hline 12. & 30 & 30 & 20 \\
\hline 13. & 60 & 50 & 20 \\
\hline 14. & 60 & 50 & 20 \\
\hline 15. & 60 & 50 & 20 \\
\hline 16. & 60 & 50 & 30 \\
\hline 17. & 30 & 50 & \\
\hline
\end{tabular}


Tablica 5 - Vrijednosti ukupnih polifenola, antiradikalne aktivnosti te udjela klorogenske kiseline i rutina u ekstraktima refabrikata prema dizajnu Box-Behnken (BBD)

Table 5 - Total phenol content and free radical scavenging activity in extracts for proposed experiments according to Box-Behnken design (BBD)

\begin{tabular}{c|c|c|c|c|c}
\hline RUN & Ukupni fenoli/mg GAE/g & \% DPPH & Klorogenska kiselina/mgg & Rutin $/ \mathrm{mgg}^{-1}$ \\
\hline 1. & 9,00 & 36,97 & 0,65 & 1,80 \\
\hline 2. & 6,75 & 29,45 & 0,55 & 1,50 \\
\hline 3. & 8,60 & 30,03 & 0,89 & 1,40 \\
\hline 4. & 11,35 & 44,68 & - & 0,70 & 0,95 \\
\hline 5. & 6,35 & 29,32 & 0,90 & 1,05 \\
\hline 6. & 5,30 & 31,42 & 0,81 & 1,35 \\
\hline 7. & 8,00 & 22,56 & 0,77 & 1,45 \\
\hline 8. & 7,00 & 31,83 & - & 1,69 \\
\hline 9. & 12,50 & 44,34 & - & 1,75 \\
\hline 10. & 14,75 & 41,60 & 0,45 & 1,21 \\
\hline 11. & 10,60 & 44,24 & 0,65 & 1,25 \\
\hline 12. & 6,75 & 30,18 & 0,45 & 1,54 \\
\hline 13. & 6,45 & 26,98 & 0,65 & 1,57 \\
\hline 14. & 6,85 & 26,73 & 0,55 & 1,53 \\
\hline 15. & 6,75 & 25,44 & 0,58 & 1,59 \\
\hline 16. & 6,65 & 24,05 & 0,85 & 1,45 \\
\hline
\end{tabular}

Prethodna istraživanja pokazala su da su klorogenska kiselina i rutin dominantni fenolni spojevi u duhanskom otpadu. ${ }^{12}$ Stoga su ti spojevi određeni i kvantificirani u dobivenim ekstraktima (tablica 5).

Metoda odzivnih površina kao skup matematičkih i statističkih tehnika već se pokazala kao koristan alat u razvoju, poboljšanju i optimizaciji procesa uz smanjenje broja potrebnih eksperimenata. ${ }^{26}$ Osim toga ta metoda je već primijenjena za optimizaciju ekstrakcije kafeinske kiseline iz duhanskog otpada, ${ }^{8}$ fenolnih spojeva i solanesola iz duhanskog otpada ${ }^{7}$ te nikotina ${ }^{10}$ i fenolnih spojeva iz duhanskog lista i otpada. Ta metoda omogućava planiranje pokusa tako da se provode samo određeni eksperimenti s unaprijed određenim kombinacijama procesnih parametara na osnovi kojih je kasnije moguće odrediti optimalne parametre procesa uz ekonomsku i energetsku uštedu. ${ }^{26}$

Da bi se ispitao utjecaj nezavisnih varijabli ekstrakcije (vremena, temperature i udjela vode u otapalu) na zavisne varijable te provjerila prikladnost primijenjenog BoxBehnkenovog plana pokusa u modeliranju i optimiranju procesa ekstrakcije, provedena je aproksimacija eksperimentalnih podataka matematičkim modelom, tj. polinomom drugog reda. Dobiveni modeli (1-4) i njihovi koeficijenti dobiveni su statističkom metodom nelinearne regresije eksperimentalnih podataka, a daju funkcionalnu ovisnost između zavisnih i nezavisnih varijabli.

U modelima su vidljivi regresijski koeficijenti dobiveni odgovarajućim eksperimentalnim podatcima polinomom drugog reda za ispitivane odzive. Koeficijenti se u ovom slučaju odnose na kodirane varijable. Vjerojatnost (p-vrijednost) tih regresijskih modela bila je ispod 0,05, što ukazuje na to da je statistički značajna veza između nezavisnih varijabli i odzivnih varijabli (tablica 6). Stupanj i smjer slaganja varijabli procjenjuje se pomoću koeficijenta korelacije. Koeficijent korelacije $R^{2}$ je pokazatelj slaganja eksperimentalnih i modelom predviđenih podataka i u idealnom slučaju iznosi $1 .{ }^{27}$

Za dobar model vrijednost koeficijenta korelacije treba biti najmanje $0,80 .{ }^{27}$ Za duhanski otpad (refabrikat) vrijednost $R^{2}$ za sve promatrane odzive bila je veća od 0,80 $(0,98$; $0,83 ; 0,95$ i 0,95$)$, što nam govori da je primijenjeni regresijski model odgovarao eksperimentalno predviđenim podatcima.

$$
\begin{aligned}
& \text { Ukupni fenoli }=66,89+9,71 X_{1}+24,14 X_{2}+18,87 X_{3}+6,73 X_{1}^{2}+15,81 X_{2}^{2}+ \\
& +16,33 X_{3}^{2}+11,41 X_{1} X_{2}-1,48 X_{1} X_{3}+1,05 X_{2} X_{3} \\
& \mathrm{DPPH}=25,73+1,81 X_{1}+3,73 X_{2}+4,39 X_{3}+1,9 X_{1}^{2}+6,47 X_{2}^{2}+6,36 X_{3}^{2}+3,16 X_{1} X_{2}+3,01 X_{1} X_{3}-2,05 X_{2} X_{3} \\
& \text { Klorogenska kiselina }=5,53-1,89 X_{1}-2,02 X_{2}-1,67 X_{3}+0,31 X_{1}^{2}-0,43 X_{2}^{2}- \\
& -0,1 X_{3}^{2}-2,08 X_{1} X_{2}-2,31 X_{1} X_{3}-0,61 X_{2} X_{3}
\end{aligned}
$$


Tablica 6 - Analiza varijance (ANOVA) promatranih odziva za duhanski otpad (refabrikat)

Table 6 - Analysis of variance (ANOVA) of second-order polynomial models for tobacco waste (scrap)

\begin{tabular}{|c|c|c|c|c|c|}
\hline Izvor varijabilnosti & $\begin{array}{c}\text { Suma kvadratnih } \\
\text { odstupanja }\end{array}$ & $\begin{array}{c}\text { Stupnjevi } \\
\text { slobode DF }\end{array}$ & Varijanca MS & F-vrijednost & $p$-vrijednost \\
\hline \multicolumn{6}{|l|}{ Ukupni fenoli } \\
\hline model & 11404,09 & 9 & 1267,12 & 52,73 & $<0,0001$ \\
\hline$X_{1}-$ vrijeme & 754,66 & 1 & 754,66 & 31,40 & 0,0008 \\
\hline$X_{2}$ - temperatura & 4663,37 & 1 & 4663,37 & 194,06 & $<0,0001$ \\
\hline$X_{3}$ - udio vode u otapalu & 2848,24 & 1 & 2848,24 & 118,53 & $<0,0001$ \\
\hline$X_{1} X_{2}$ & 520,75 & 1 & 520,75 & 21,67 & 0,0023 \\
\hline$X_{1} X_{3}$ & 8,70 & 1 & 8,70 & 0,3621 & 0,5663 \\
\hline$X_{2} X_{3}$ & 4,39 & 1 & 4,39 & 0,1826 & 0,6819 \\
\hline$X_{1}^{2}$ & 190,83 & 1 & 190,83 & 7,94 & 0,0258 \\
\hline$X_{2}^{2}$ & 1053,08 & 1 & 1053,08 & 43,82 & 0,0003 \\
\hline$X_{3}^{2}$ & 1122,78 & 1 & 1122,78 & 46,72 & 0,0002 \\
\hline ostatak & 168,21 & 7 & 24,03 & & \\
\hline nedostatak modela & 166,94 & 3 & 55,65 & 175,17 & 0,0001 \\
\hline pogreška & 1,27 & 4 & 0,3177 & & \\
\hline ukupno & 11572,31 & 16 & & & \\
\hline$R^{2}$ & 0,9855 & & & & \\
\hline \multicolumn{6}{|l|}{ Antiradikalna aktivnost } \\
\hline model & 779,01 & 9 & 86,56 & 3,93 & 0,0423 \\
\hline$X_{1}$ - vrijeme & 26,21 & 1 & 26,21 & 1,19 & 0,3113 \\
\hline$X_{2}$ - temperatura & 111,08 & 1 & 111,08 & 5,05 & 0,0595 \\
\hline$X_{3}$ - udio vode u otapalu & 154,09 & 1 & 154,09 & 7,00 & 0,0331 \\
\hline$X_{1} X_{2}$ & 40,07 & 1 & 40,07 & 1,82 & 0,2192 \\
\hline$X_{1} X_{3}$ & 36,24 & 1 & 36,24 & 1,65 & 0,2402 \\
\hline$X_{2} X_{3}$ & 16,77 & 1 & 16,77 & 0,7620 & 0,4116 \\
\hline$X_{1}^{2}$ & 15,18 & 1 & 15,18 & 0,6898 & 0,4336 \\
\hline$X_{2}^{2}$ & 176,05 & 1 & 176,05 & 8,00 & 0,0255 \\
\hline$X_{3}^{2}$ & 170,38 & 1 & 170,38 & 7,74 & 0,0272 \\
\hline ostatak & 154,04 & 7 & 22,01 & & \\
\hline nedostatak modela & 148,50 & 3 & 49,50 & 35,69 & 0,0024 \\
\hline pogreška & 5,55 & 4 & 1,39 & & \\
\hline ukupno & 933,06 & 16 & & & \\
\hline$R^{2}$ & 0,8349 & & & & \\
\hline \multicolumn{6}{|l|}{ Klorogenska kiselina } \\
\hline model & 124,76 & 9 & 13,86 & 15,09 & 0,0008 \\
\hline$X_{1}$ - vrijeme & 28,46 & 1 & 28,46 & 30,97 & 0,0008 \\
\hline$X_{2}$ - temperatura & 32,76 & 1 & 32,76 & 35,66 & 0,0006 \\
\hline$X_{3}$ - udio vode u otapalu & 22,18 & 1 & 22,18 & 24,13 & 0,0017 \\
\hline$X_{1} X_{2}$ & 17,35 & 1 & 17,35 & 18,88 & 0,0034 \\
\hline$X_{1} X_{3}$ & 21,34 & 1 & 21,34 & 23,23 & 0,0019 \\
\hline$X_{2} X_{3}$ & 1,49 & 1 & 1,49 & 1,62 & 0,2438 \\
\hline$X_{1}^{2}$ & 0,4053 & 1 & 0,4053 & 0,4410 & 0,5279 \\
\hline$X_{2}^{2}$ & 0,7776 & 1 & 0,7776 & 0,8462 & 0,3882 \\
\hline$X_{3}^{2}$ & 0,0440 & 1 & 0,0440 & 0,0479 & 0,8330 \\
\hline ostatak & 6,43 & 7 & 0,9189 & & \\
\hline nedostatak modela & 3,40 & 3 & 1,13 & 1,50 & 0,3439 \\
\hline pogreška & 3,03 & 4 & 0,7580 & & \\
\hline ukupno & 131,20 & 16 & & & \\
\hline$R^{2}$ & 0,9510 & & & & \\
\hline \multicolumn{6}{|l|}{ Rutin } \\
\hline model & 85,88 & 9 & 9,54 & 14,58 & 0,0009 \\
\hline$X_{1}$ - vrijeme & 16,94 & 1 & 16,94 & 25,88 & 0,0014 \\
\hline$X_{2}$ - temperatura & 3,03 & 1 & 3,03 & 4,62 & 0,0686 \\
\hline$X_{3}$ - udio vode u otapalu & 61,94 & 1 & 61,94 & 94,64 & $<0,0001$ \\
\hline$X_{1} X_{2}$ & 0,0049 & 1 & 0,0049 & 0,0075 & 0,9335 \\
\hline$X_{1} X_{3}$ & 0,1849 & 1 & 0,1849 & 0,2825 & 0,6115 \\
\hline$X_{2} X_{3}$ & 0,8281 & 1 & 0,8281 & 1,27 & 0,2977 \\
\hline
\end{tabular}




\begin{tabular}{|c|c|c|c|c|c|}
\hline Izvor varijabilnosti & $\begin{array}{c}\text { Suma kvadratnih } \\
\text { odstupanja }\end{array}$ & $\begin{array}{c}\text { Stupnjevi } \\
\text { slobode DF }\end{array}$ & Varijanca MS & F-vrijednost & $p$-vrijednost \\
\hline$X_{1}{ }^{2}$ & 2,39 & 1 & 2,39 & 3,65 \\
\hline$X_{2}{ }^{2}$ & 0,0033 & 1 & 0,0033 & 0,0050 & 0,9454 \\
\hline$X_{3}^{2}$ & 0,4258 & 1 & 0,4258 & 0,6506 \\
\hline ostatak & 4,58 & 7 & 0,6545 & \\
\hline nedostatak modela & 4,57 & 3 & 1,52 & 602,27 \\
\hline pogreška & 0,0101 & 4 & 0,0025 & \\
\hline ukupno & 90,46 & 16 & & \\
\hline$R^{2}$ & 0,9494 & & & \\
\hline
\end{tabular}

Vrijeme miješanja $\left(X_{1}\right)$, temperatura $\left(X_{2}\right)$ i udio vode $u$ otapalu $\left(X_{3}\right)$ imaju statistički značajan utjecaj $(p<0,05)$ na ukupan udio fenola. Kombinacija vremena miješanja i temperature $\left(X_{1} X_{2}\right)$ također je imala značajan utjecaj na udio fenola, kao i kvadratne vrijednosti triju parametara, $X_{1}{ }^{2}, X_{2}{ }^{2}, X_{3}{ }^{2}$. Za antiradikalnu aktivnost udio vode $\mathrm{u}$ otapalu imao je statistički značajan utjecaj, kao i kvadrati vrijednosti vremena miješanja $X_{2}{ }^{2} \mathrm{i}$ udjela vode $\mathrm{u}$ otapalu $X_{3}{ }^{2}(p<0,05)$. Uspoređujući dobivene rezultate s onim iz Jokić i sur., ${ }^{10}$ gdje je na istoj vrsti duhanskog otpada primjenjivana tehnika ekstrakcije subkritičnom vodom, može se uvidjeti da je temperatura imala statistički značajan utjecaj na antiradikalnu aktivnost i sadržaj ukupnih fenola kod primjene obje tehnike ekstrakcije. Razlog tomu je što su nositelji antiradikalne aktivnosti u duhanu, a samim time i u duhanskom otpadu, upravo fenolni spojevi. S obzirom na to da su fenolni spojevi često termolabilni, na višim temperaturama dolazi do njihove degradacije, a posljedično i promjene u antiradikalnoj aktivnosti i sadržaju ukupnih fenola., ${ }^{8,12}$ Analizom promatranih odziva za sadržaj klorogenske kiseline vidljivo je da svi parametri $\left(X_{1}, X_{2}\right.$ i $\left.X\right)$ pojedinačno imaju statistički značajan utjecaj na sadržaj klorogenske kiseline $(p<0,05)$, kao i kombinacija parametara vremena $\mathrm{i}$ temperature miješanja $\left(X_{1} X_{2}\right)$ te vremena miješanja i udjela vode u otapalu $\left(X_{1} X_{3}\right)$. Temperatura je imala negativan utjecaj na sadržaj klorogenske kiseline. Sličan trend opadanja sadržaja klorogenske kiseline s porastom

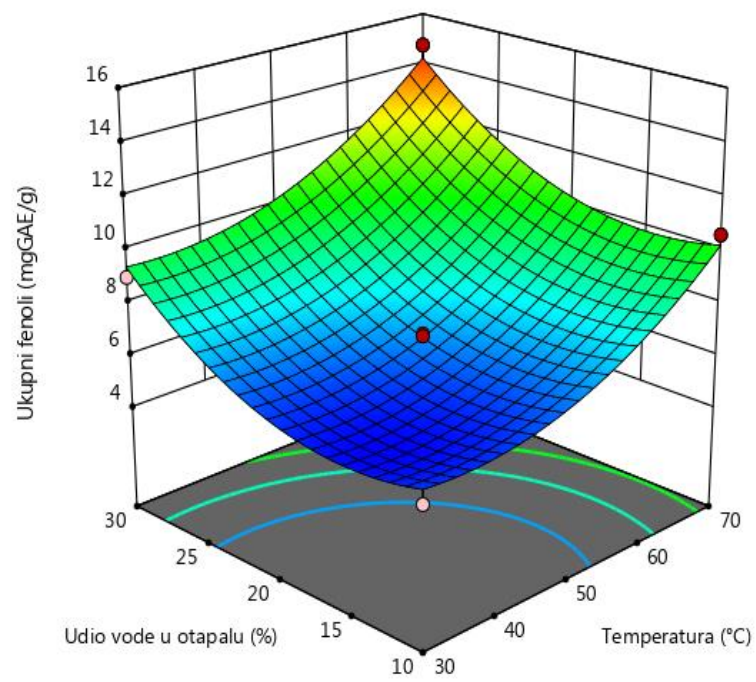

temperature ekstrakcije uočena je i kod drugih autora gdje je primijenjena ekstrakcija klorogenske kiseline iz lišća krumpira $^{27} \mathrm{i}$ duhanskog otpada. ${ }^{10} \mathrm{~S}$ obzirom na to da se kompletna degradacija klorogenske kiseline odvija na temperaturama iznad $180^{\circ} \mathrm{C}$, a ekstrakcija eutektičkim otapalima podrazumijeva relativno niske temperature, degradacija klorogenske kiseline nije bila toliko izražena. $\mathrm{Na}$ sadržaj rutina statistički značajan utjecaj imali su vrijeme miješanja $\left(X_{1}\right)$ i udio vode u otapalu $\left(X_{3}\right)$.

Za bolji prikaz utjecaja parametara (temperature, vremena miješanja i udjela vode u otapalu) na zavisne varijable (udio fenola, antiradikalnu aktivnost, udio klorogenske kiseline i rutina) unutar ispitivanog područja konstruirani su 3D dijagrami (slike 1 - 8).

Povećanje udjela vode u otapalu također je djelovalo na smanjenje udjela klorogenske kiseline. Slični rezultati dobiveni su u istraživanju Wang $i$ sur., ${ }^{12}$ gdje je omjer tekuće kruto imao najveći utjecaj na udio klorogenske kiseline u duhanskom otpadu gdje je manji omjer tekuće kruto također značajno utjecao na povišenje udjela klorogenske kiseline. S druge strane, povišenje udjela vode u otapalu kao i povećanje razdoblja zagrijavanja utjecalo je na povišenje udjela rutina. Sličan pozitivan utjecaj na udio rutina u duhanskom otpadu zabilježen je i u našem prethodnom istraživanju, gdje je za ekstrakciju rutina upotrijebljena ultrazvučna kupelj.?

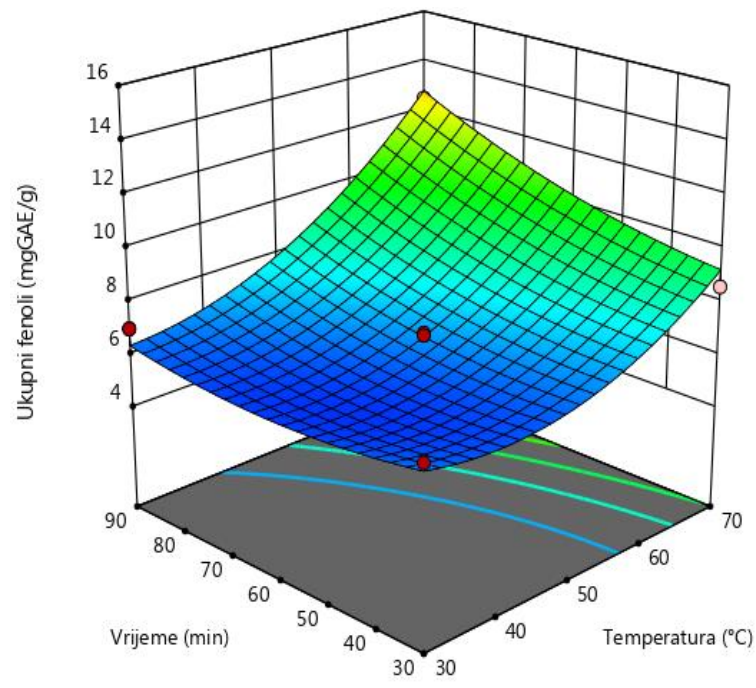



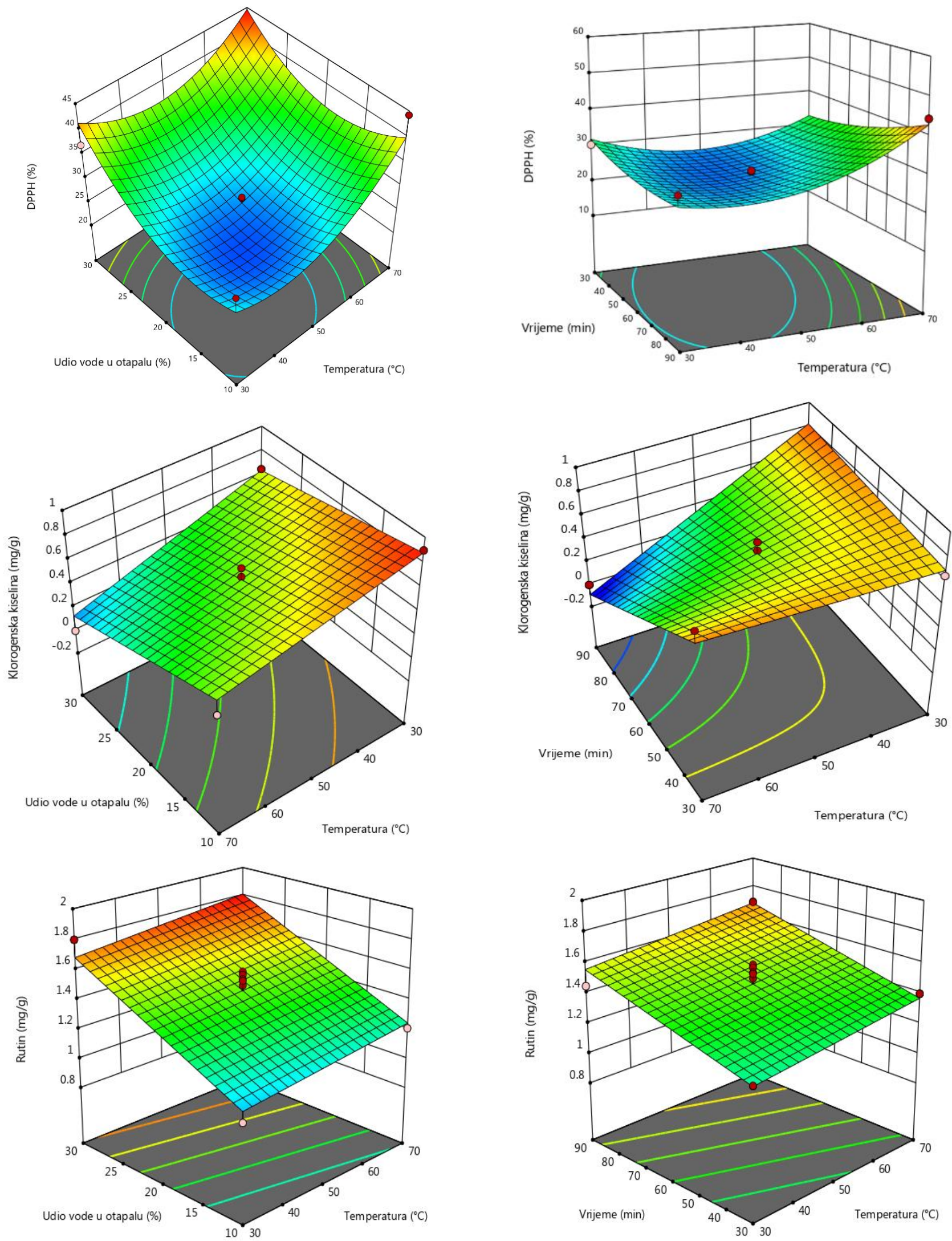

Slike 1-8 - Trodimenzijski (3D) dijagrami utjecaja ispitivanih varijabli na promatrane odzive

Figs. 1-8 - Three-dimensional (3D) response surface plots for dependent variables as a function of independent variables 
Kao konačni cilj metode odzivnih površina provedena je optimizacija procesa. Pri tome su parametri postavljeni tako da se postigne maksimalan udio ukupnih fenola i maksimalna antiradikalna aktivnost te maksimalan sadržaj klorogenske kiseline i rutina. Primjenom funkcionalne metode (engl. desirability function method) ${ }^{28}$ definirani su optimalni uvjeti ekstrakcije, koji iznose 30 min (vrijeme miješanja), $70{ }^{\circ} \mathrm{C}$ (temperatura miješanja) i $29 \%$ vode u otapalu.

\section{Zaključak}

Ekstrakcija eutektičkim otapalima pokazala se pogodnom za ekstrakciju bioaktivnih komponenti iz duhanskog otpada, a metoda odzivnih površina vrlo učinkovitom u modeliranju i optimiranju ovog procesa ekstrakcije. Procesni parametri (temperatura miješanja, vrijeme miješanja i udio vode u otapalu) utječu na iskorištenje ekstrakcije, odnosno na udio fenola, antiradikalnu aktivnost, udio klorogenske kiseline i rutina, u duhanskom otpadu. Provedeno istraživanje ukazuje na mogućnost ekonomičnijeg upravljanja duhanskim industrijskim otpadom, tijekom kojeg se ta vrsta otpada iskorištava na novi, ekološki prihvatljiv način.

\section{Popis kratica i simbola List of abbreviations and symbols}

\begin{tabular}{|c|c|}
\hline ANOV & - analiza varijance \\
\hline & - analysis of variance \\
\hline DES & - eutektička otapala \\
\hline & - deep eutectic solvents \\
\hline DPPH & -2,2-difenil-I-piklorhidrazil \\
\hline & -2,2-diphenyl-1-picrylhydrazyl \\
\hline GAE & - ekvivalenti galne kiseline \\
\hline & - gallic acid equivalent \\
\hline HPLC & - tekućinska kromatografija visoke djelotvornost \\
\hline & - High Performance Liquid Chromatography \\
\hline LOD & - granica detekcije \\
\hline & - limit of detection \\
\hline LOQ & - granica kvantifikacije \\
\hline & - limit of quantification \\
\hline
\end{tabular}

\section{ZAHVALA}

Ovaj rad sufinancirala je Hrvatska zaklada za znanost projektom "Primjena inovativnih tehnika ekstrakcije bioaktivnih komponenti iz nusproizvoda biljnoga podrijetla" (UIP-2017-05-9909).

\section{Literatura}

\section{References}

1. W. Wang, P. Xu, H. Tang, Sustainable production of valuable compound 3-succinoyl-pyridine by genetically engineering Pseudomonas putida using the tobacco waste, Sci. Rep. 5 (2015) 16411, doi: https://doi.org/10.1038/srep16411.

2. M. Banožić, E. Nukić-Hrastovina, S. Jokić, Neke mogućnosti iskorištenja nusproizvoda duhanske industrije, u Neke mogućnosti iskorištenja nusproizvoda prehrambene industrije, Sveučilište Josipa Jurja Strossmayera u Osijeku, Prehrambeno-tehnološki fakultet Osijek, 2019. str. 219-240.

3. J. L. Valverde, C. Curbelo, O. Mayo, C. B. Molina, Pyrolysis kinetics of tobacco dust, Chem. Eng. R. 78 (2000) 921-924, doi: https://doi.org/10.1205/026387600527996.

4. D. Zielke, R. Liebe, The Removal of Stems from Cut Tobacco, J. BTFI GmbH 17 (1997) 49-55, doi: https://doi.org/10.2478/cttr-2013-0655.

5. R. Barrena, F. Vazquez, A. Sanchez, Dehydrogenase activity as a method for monitoring the composting process, Bioresour. Technol. 99 (2008) 905-908, doi: https://doi.org/10.1016/j.biortech.2007.01.027.

6. E. Benitez, R. Nogales, C. Elvira, G. Masciandaro, B. Ceccanti, Enzyme activities as indicators of the stabilization of sewage sludge composting with Eisenia foetida, Bioresour. Technol. 67 (1999) 297-303, doi: https://doi.org/10.1016/S0960-8524(98)00117-5.

7. M. Banožić, I. Banjari, M. Jakovljević, D. Šubarić, S. Tomas, J. Babić, S. Jokić, Optimization of ultrasound-assisted extraction of some bioactive compounds from tobacco waste, Molecules 24 (2019) 1611, doi: https://doi.org/10.3390/molecules24081611.

8. J. Wang, D. Lu, H. Zhao, X. Ling, B. Jiang, P. Ouyang, Application of response surface methodology optimization for the production of caffeic acid from tobacco waste, Afr. J. Biotechnol. 8 (2009) 1416-1424.

9. Y. Chen, Q. Jimmy Yu, X. Li, Y. Luo, H. Liu, Extraction and HPLC characterization of chlorogenic acid from tobacco residuals, Sep. Sci. Technol. 42 (2007) 3481-3492, doi: https://doi.org/10.1080/01496390701626677.

10. S. Jokić, T. Gagić, Ž. Knez, M. Banožić, M. Škerget, Separation of active compounds from tobacco waste using subcritical water extraction, J. Supercrit. fluids 153 (2019) 104593, doi: https://doi.org/10.1016/j.supflu.2019.104593.

11. P. P. Mumba, R. Phiri, Environmental Impact Assessment of Tobacco Waste Disposal, Int. J. Environ. Res. 2 (2008) 225230.

12. J. Wang, D. Lu, H. Zhao, B. Jiang, J. Wang, X. Ling, H. Chai, P. Ouyang, Discrimination and classification of tobacco wastes by identification and quantification of polyphenols with LCMS/MS. J. Serb. Chem. Soc. 75 (2010) 875-891, doi: https://doi.org/10.2298/jsc091109055w.

13. F. Fathiazad, A. Delazar, R. Amiria, S. D. Sarkerb, Extraction of Flavonoids and Quantification of Rutin from waste Tobacco Leaves, Iran. J. Pharm. Res. 3 (2006) 222-227, doi: https://doi.org/10.22037/IJPR.2010.680.

14. L. Gobbo-Neto, N. P. Lopes, Online identification of chlorogenic acids, sesquiterpene lactones, and flavonoids in the Brazilian Arnica Lychnophora ericoides Mart. (Asteraceae) leaves by HPLC-DAD-MS and HPLC-DAD-MS/MS and a validated HPLC-DAD method for their simultaneous analysis, J. Agric. Food Chem. 56 (2008) 1193-1204, 
doi: https://doi.org/10.1021/jf072812l.

15. Y. Dai, J. Spronsen, G. J. Witkamp, R. Verpoorte, Y. H. Choi, Natural Deep Eutectic Solvents as new potential media for green technology, Anal. Chim. Acta 766 (2013) 61-68, doi: https://doi.org/10.1016/j.aca.2012.12.019.

16. G. Cravotto, L. Boffa, S. Mantegna, P. Perego, M. Avogadro, P. Cintas, Improved extraction of vegetable oils under highintensity ultrasound and/or microwaves, Ultrason. Sonochem. 5 (2008) 898-902, doi: https://doi.org/10.1016/j.ultsonch.2007.10.009.

17. F. Chemat, M. A. Vian, G. Cravotto, Green extraction of natural products: Concept and principles, Int. J. Mol. Sci 13 (2012) 8615-8627, doi: https://doi.org/10.3390/ijms13078615.

18. E. L. Smith, A. P. Abbott, K. S. Ryder, Deep Eutectic Solvents (DESs) and their Applications, Chem. Rev. 114 (2014) 1106011082, doi: https://doi.org/10.1021/cr300162p.

19. A. P. Abbott, G. Capper, S. Gray, Design of Improved Deep Eutectic Solvents Using Hole Theory, Chem. Phys. Chem. 7 (2006) 803-806, doi: https://doi.org/10.1002/cphc.200500489.

20. M. Molnar, I. Jerković, D. Suknović, B. Bilić Rajs, K. Aladić, D. Šubarić, S. Jokić, Screening of Six Medicinal Plant Extracts Obtained by Two Conventional Methods and Supercritical $\mathrm{CO}_{2}$ Extraction Targeted on Coumarin Content, 2,2Diphenyl-1-picrylhydrazyl Radical Scavenging Capacity and Total Phenols Content, Molecules 22 (2017) 348-1, doi: https://doi.org/10.3390/molecules22030348.

21. H. Shekaari, M. T. Zafarani-Moattar, A. Shayanfar, M. Mokhtarpour, Effect of choline chloride/ethylene glycol or glycerol as deep eutectic solvents on the solubility and thermodynamic properties of acetaminophen, J. Mol. Liq. 249 (2018) 1222-1235, doi: https://doi.org/10.1016/j.molliq.2017.11.057.

22. M. E. Alañón, M. Ivanović, A. M. Gómez-Caravaca, D. ArráezRomán, A. Segura-Carretero, Choline chloride derivativebased deep eutectic liquids as novel green alternative solvents for extraction of phenolic compounds from olive leaf, Arab. J. Chem. 13 (2020) 1685-1701, doi: https://doi.org/10.1016/j.arabjc.2018.01.003.

23. B. Ozturk, C. Parkinson, M. Gonzalez-Miquel, Extraction of polyphenolic antioxidants from orange peel waste using deep eutectic solvents, Sep. Purif. Technol. 206 (2018) 1-13, doi: https://doi.org/10.1016/j.seppur.2018.05.052.

24. B. Xia, D. Yan, Y. Bai, J. Xie, Y. Cao, D. Liao, L. Lin, Determination of phenolic acids in Prunella vulgaris L.: A safe and green extraction method using alcohol-based deep eutectic solvents, Anal. Methods 7 (2015) 9354-9364, doi: https://doi.org/10.1039/C5AY02035B.

25. H. Zhang, B. Tang, K. Row, Extraction of catechin compounds from green tea with a new green solvent, Chem. Res. Chin. Univ. 30 (2014) 37-41, doi: https://doi.org/10.1007/s40242-014-3339-0.

26. K. M. Carley, N. Y. Kamneva, J. Reminga, Response surface methodology, CASOS Technical Report, Carnegie Mellon University, 2004., str. 1-24, doi: https://doi.org/10.21236/ ADA459032.

27. P. P. Singh, M. D. A. Saldana, Subcritical water extraction of phenolic compounds from potato peel, Food Res. Int. 44 (2011) 2452-2458, doi: https://doi.org/10.1016/j.foodres.2011.02.006.

28. D. Bas, I. H. Boyaci, Modeling and optimization I: Usability of response surface methodology, J. Food Eng. 78 (2007) 836845, doi: https://doi.org/10.1016/j.jfoodeng.2005.11.024.

\title{
SUMMARY
}

\author{
Extraction of Bioactive Compounds from Tobacco Waste using Deep Eutectic Solvents \\ Marija Banožić, a* Maja Matić, Silvija Šafranko, Ana-Marija Cikoš, Martina Jakovljević, Maja Molnar, a and Stela Jokića
}

Tobacco waste is a solid waste highly diverse in granulation and point of separation in the manufacturing process. The objective of this study was to investigate the efficacy of eutectic solvents in the extraction of bioactive compounds from tobacco waste. Influence of extraction parameters on the properties of the obtained extracts (total phenol, antioxidant activity, chlorogenic acid, and rutin) has been determined. Using response surface methodology, optimal parameters were defined ( $30 \mathrm{~min}, 70{ }^{\circ} \mathrm{C}, 29.99 \%$ water). The meaning of the proposed research is reflected in the maximum utilization of the tobacco by-product in order to obtain extracts that can be implemented in other products and processes.

\section{Keywords}

Tobacco waste, deep eutectic solvents, extraction, bioactive compounds

\footnotetext{
${ }^{a}$ Faculty of Food Technology Osijek, Josip Juraj Strossmayer University of Osijek, Republic of Croatia

b University of Mostar, Faculty of Agriculture and Food Technology Mostar, Bosnia and Herzegovina
}

Original scientific paper

Received February 25, 2020

Accepted May 19, 2020 